\title{
RESEARCH IN THE FIELD OF MEDICINE THAT ELICIT LEGISLATIVE CHANGES IN THE HEALTH BUDGET
}

\section{Dana Sonia Oieru,}

\author{
D.S. Oieru , R.A. Popa
}

*Correspondence:

$\mathrm{PhD}$ student, University of Oradea, Faculty of Medicine

The Doctoral School of the University of Oradea, Faculty of Medicine Iacobinilor str., no $12 \mathrm{~A}$, postal code 410251, Oradea, Bihor county. tel. no: +40742139284

email address: oierusonia@yahoo.com

\section{Remus Amorin Popa}

*Correspondence:

Professor, University of Oradea, Faculty of Medicine, Chief of Doctoral Medical School The Doctoral School of the University of Oradea, Faculty of Medicine Iacobinilor str., no 12 A, postal code 410251, Oradea, Bihor county.

\begin{abstract}
Regarding the psychological factors as etiologic agents that trigger the somatic diseases has gained more and more ground in the past few years, successfully repeating that the human being is a bio-psycho-social entity. In order to render the psychological interventions more efficient for the management of the diabetes mellitus diseases, we must detect and modify those configurations of the early maladaptive schemes and coping styles that stick together in the socalled acquired vulnerability which makes the person liable to an inappropriate reaction against stress.
\end{abstract}

Keywords: acquired vulnerability, coping style, adaptive weakness, management of the disease, psychological intervention.

\section{Introduction}

The ground-breaking progress achieved within the sciences whose object is the health condition, is the consequence of a revolution in theory and practice and forms the basis of a radical change of the traditional notions about the human nature of the health condition and disease. In the centre of this revolution rests the human behavior and its determinations in the social framework and the existence of different criteria for understanding the etiology, treatment and prevention of many medical disorders assigned to biological causes only.

This revolution encourages the development and growth of the multidisciplinary approaches, including the psychology of health condition, medical psychology, medical behavior.

Background and Aims: A great number of paper was dedicated to the mood-based psychosomatic diseases and the role of negative affectivity'. Many researches in ' 80 years were focused on a mood the authors called "negative affectivity" (NA). The subjects with NA show a high level of discomfort and dissatisfaction, are introspective, linger upon their failures and mistakes, tend to be negative, focusing on the negative aspects of themselves and of the others. Negative affectivity has similar features with other dispositional typologies, such as neuroticism, anxiety, pessimism, maladaptation ${ }^{[1-4]}$

${ }^{1}$ Flaxman F.E., Blackledge J.T., Bond F. Acceptance and commitment therapy, "Routledge" Press, New York, 2011; 


\section{THAT ELICIT LEGISLATIVE CHANGES IN THE HEALTH BUDGET}

Positive affectivity would be the contrary of the negative one, associated with extraversion, higher energetic level, superior activity level. Very recent researches show that individuals with intense negative affectivity seem to be hypervigilant with their own bodies and have a low threshold when it comes to notice and report discrete somatic sensations. Their pessimistic worldview makes them more concerned about the implications of the situations perceived and they seem to have a higher risk for somatization and hypochondria. These individuals are more likely to report symptoms in all the situations and across long periods of time, the temporary situational stressors having but a small influence upon this stable personality trait. Negative affectivity is one of the problems that influences negatively both the assessment of symptomps description and the clinical and research studies.

In the past years the psychosomatic approaches have gained ground. Among others, they highlight the role of the immunogenic personality traits - locus of control, self-efficacy, hardiness, self-esteem - in triggering certain diseases. The term "locus of control" was introduced in 1966 and named "the way in which a person explains their success or failure, through controllable or uncontrollable internal or external causes." ${ }^{2}$ Internal locus of control means that both responsibility for the errors and merit for success are due more to the flaws, errors and respectively to the abilities, knowledge and skills of the person and less to the external factors; external locus of control overestimates the importance of the person's external factors (chance, destiny, divinity etc) in defining success or failure. Starting from these two categories of locus of control, there are attempts to make inferences to the efficacy of the coping. Thus, ILC would function as a protection in case of acute and chronic stress through the increased level of responsiveness to the environmental information that has great adaptive value, through resistance to external pressure and the high level of adapting to the situation. Other authors think that personal responsibility configured in ILC is an important factor in social medicine. Correlatively, ELC is a vulnerability factor to dissatisfaction and failure, leading frequently to anxiety and depression. ${ }^{[5-14]}$

Self-efficacy consists of a person's belief that they have certain motivational and cognitive skills they can activate to accomplish the planned goals. High self-efficacy is associated with high motivation and increase of the individual's real possibilities to find best solutions, while low self-efficacy is associated with failure, self-blame, depression and anxiety. Moreover, there are researches showing direct proportion between self-efficacy and the performance of the immune system, and especially of T cells, NK subpopulation.

Hardiness directly refers to the efficacy of coping mechanisms through ILC, commitment and persistence to task and perception of life changes as challenges, not fatality.

Self-esteem has been defined as a person's positive or negative self-assessment, expressed through different degrees of approval/disapproval, showing the measure to which the person sees themselves as being able, worthy, important. Starting from the hierarchical model of self-esteem, it is postulate that besides the global self-esteem we can identify the assessment of one's own value in different fields of activities. Depeding on the hierarchy and respectively the importance of those fields for defining the self, they contribute with different weight values to structuring and expressing the overall self-esteem. Success raises the levels of self-valuation and personal value, therefore of the self-esteem, while the failure lowers these levels. Low selfesteem is part of a negative affectivity, where negative expectations lead to low performances and failures. These in their turn have negative effect upon the level of self-esteem. In stressful situations, persons with anxiety and low self-esteem may have less success and can therefore experience feelings of failure. ${ }^{[15-20]}$

For this purpose we also speak about psychological vulnerability to stress and identify individuals with cognitive patterns that make them more sensitive to stress; the cognitive pattern reflects dependence on achievements or external sources of expressing the

\footnotetext{
2 Wehrenberg, M. - The 10 Best ever Depression Management Techniques, "W.W. Norton\& Company" Press, 2010 ;
} 


\section{D.S. Oieru , R.A. Popa}

way in which the individual makes a self-assessment. Such dependence upon concrete achievements or other individuals for self-assessment is opposed to the idea that states the role of the character and inborn qualities and makes the sense of self-worth vulnerable to the others' whimsical mood or life's hardships. Psychological vulnerability emphasizes the cognitive vulnerability correlated with the perceptions of dependence, perfectionism, negative attributions and the need for external sources of approval.

Psychosocial researchers looked for different connections between the cognitive vulnerability and the psychological crisis, namely the depression. A group of variable personality traits that were investigated as specific vulnerability factors to depression includes dependence, self-blame, perfectionism and dysfunctional attributions. The self-oriented perfectionism and the concerns about the individual achievements were the focus of many studies regarding vulnerability to depression.

For individuals with excessive concern for achievement, the failure recorded in comparison with important accomplishments may be an overwhelming blow leading to depression. Dependence and interpersonal sensitivity were also the focus of some researchers who found out that individuals with high score in sociotropy (or social dependence) recorded a high score in measuring the self-defence personality traits and had a more important negative perception of themselves, the world and the future. It is speculated that threats to relations may be an important source for depression in this category of subjects. Other examiners focused on the role of dysfunctional attitudes (negative, rigid thinking and mostly negative perception of self, the world and the future) in the development of depression.

In psychology stress aims at dysfunctional psychological moods caused by the difficulties the individual has to face, while the coping aims at the mechanisms and means they have at hand in order to manage these problems. Coping or stress management consists in the cognitive and behavioural effort the person makes to decrease, control or tolerate the internal or external demands which exceed the personal resources; it takes place in three stages: anticipation (warning), confrontation (impact) and postconfrontation. Coping is a response to a threat appraisal, being defined as a set of cognitive and behavioural efforts to manage the specific internal and/or external demands that were assessed as exhausting or exceeding the individual's resources. ${ }^{3}$

The research aims to highlight the role that psychological intervention has in diabetes mellitus management, especially in the first year of disease onset. Changes targeted by cognitive and behavioral psychological interventions relates mainly to change coping mechanisms, to change early maladaptive schemas and modify personality traits vulnerable to disease.

Taking into account all these aspects, physical amelioration of a disease is not enough, if it doesn't lead to the improvement of the subjects quality of life too. It is essential to approach the emotional, cultural and social aspects of each disease. The patients spiritual life must not be excluded, since its impact upon the health of the human body is a major one.

Even if the patients are still sceptical and reserved when they are being explained the psychological causes of their diseases, the medical progress that aim at the capacity of localizing in the brain the excitation or inhibition focal points correlated with certain emotions, will give more credit to the psychosomatic approach. Thus one could interfere and control diseases that seem to turn into epidemic, like it is the case of type 2 diabetes mellitus mentioned in the present paper. Within the theme of the discourse, the prevention, as well as the therapeutic intervention, should mandatory aim at the development of some abilities of coping with stress in a problemoriented manner, that would keep patients away from the urge of eating compulsively or hyperphagic eating behaviour of buying, with the price of the extra weight and the alarming values of the blood sugar, the ephemeral illusion of balance and harmony. ${ }^{[28-38]}$

\footnotetext{
${ }^{3}$ Davey, GCL, Wells, A - Worry and its Psychological Disorders: Theory, Assesment and Treatment, "J.Wiley \& Sons" Press, 2006;
} 


\section{RESEARCH IN THE FIELD OF MEDICINE \\ THAT ELICIT LEGISLATIVE CHANGES IN THE HEALTH BUDGET}

Methods. Work hypothesis: there are statistically significant differences between the two groups regarding the evolution of the quality of life of the diabetes mellitus patients after taking a CBT psychotherapeutic treatment and, in the same time, decrease the costs of medical and social treatment. The patients in the experimental group (114 subjects) benefited from 10-12 CBT and schema therapy sessions, unlike the 120 ones in the control group who followed only a drug-based treatment. The sessions took place in individual setting, one session per week. Checking the stability in time of the effects of the psychotherapy was done on a period of 6 months through follow-up session, one per month. We accurately observed the variables that could contribute to the change of the final answers (events with major impact upon life, such as the change of job, partner, house, special loss/gain, etc). Psychological instruments was NEO-PI R (personality inventory), COPE (Lazarus Folkman coping mechanism inventory), Young Questionnaires for early maladaptatives schemes.

\section{Results and interpretation.}
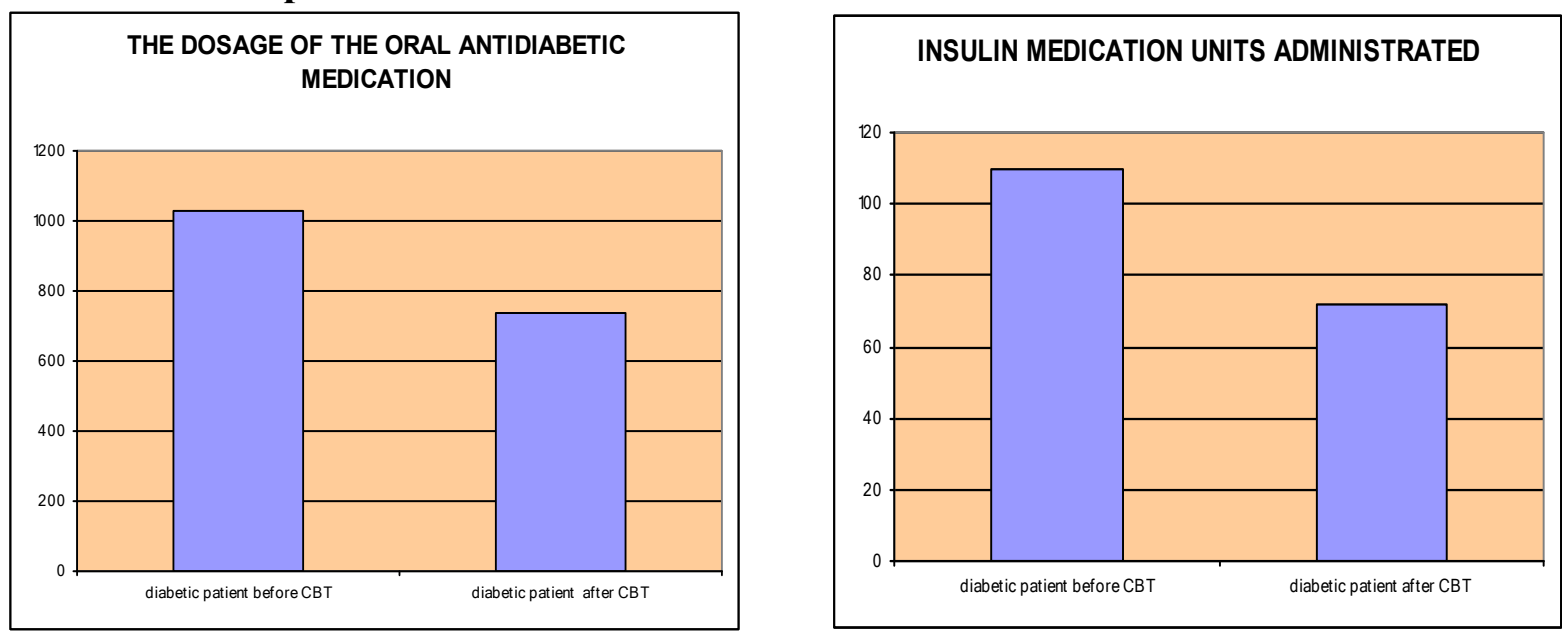

Fig. no 1 The dosage of the oral antidiabetic medication units administrated

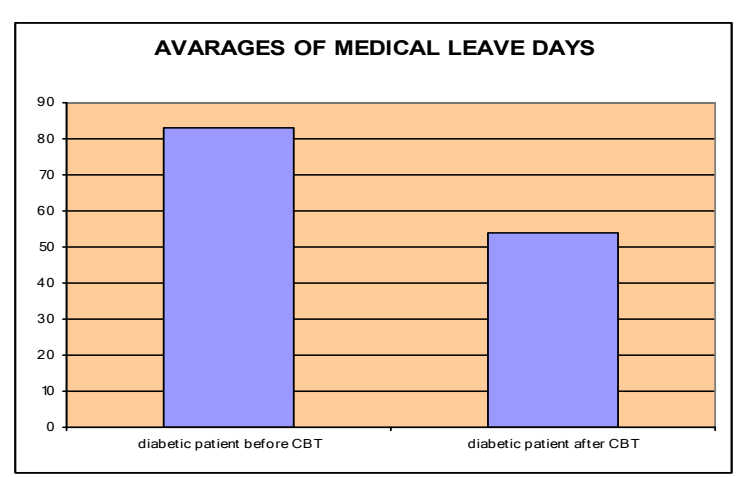

Fig. no. 3 Averages of medical leave days comorbidities

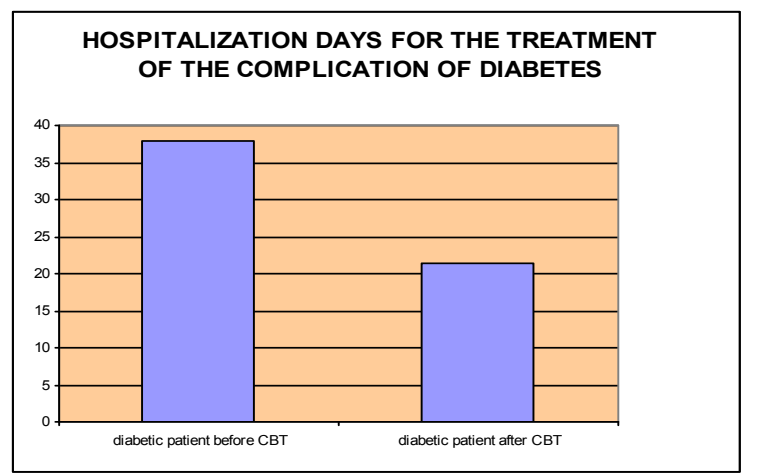

Fig. no. 4 Hospitalization for complications or 

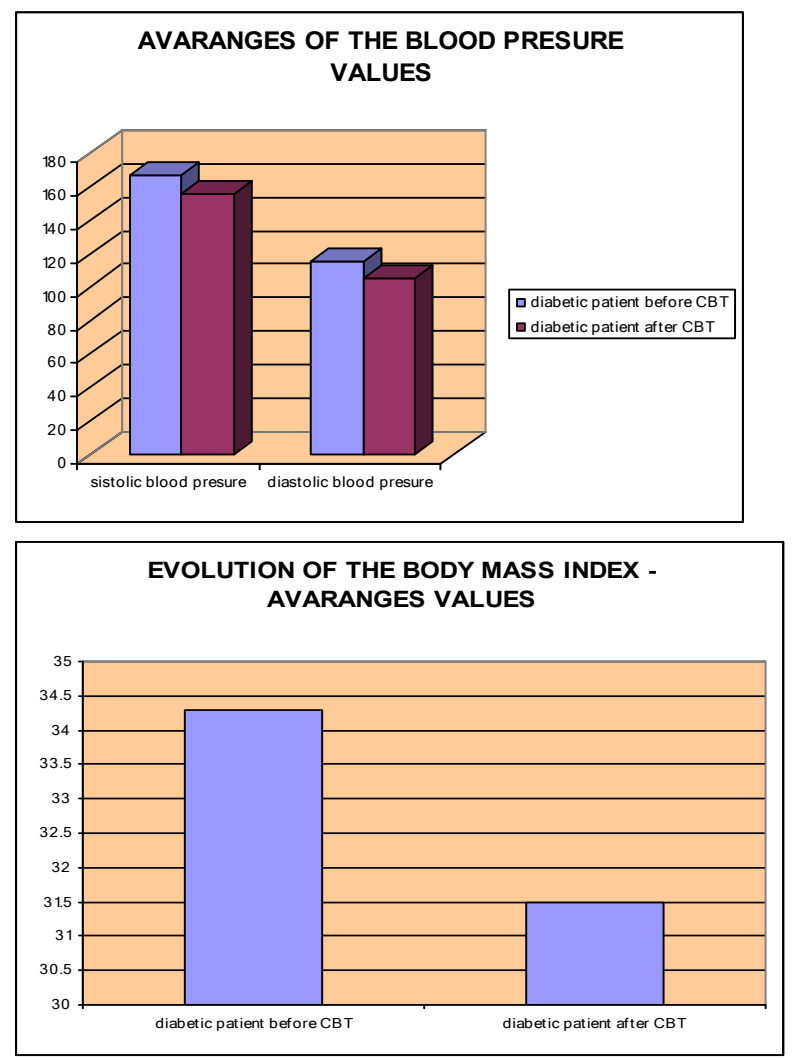

Fig. no. 5. Averages of the blood pressure values mass index avarages

Fig. no. 6 Evolution of the body

The T-test for paired and variance analysis (ANOVA) points out that the evolution of the quality of life of the diabetes mellitus patients that benefited from psychological interventions is a very good one, the changes being spectacular here and there. Significant changes were recorded as regards the answers at the personality inventory, the most obviously modified were the neuroticism factor (the anxiety, fury/hostility, depression, vulnerability to stress aspects have significantly smaller scores after CBT), the extroversion factor (the assertiveness and positive emotions aspects recorded significant growth) and the likeability factor (by increasing the scores in the trust in the others and frankness aspects). The most spectacular changes occurred in the early maladaptive schemes that significantly remitted after the psychotherapy session, as well as in the evolution of the coping mechanisms, meaning the patients acquired more efficient methods of coping with stress. The quality of life of the patients in the experimental group recorded remarkable positive changes, both by increasing the compliance with treatment, changing the perspective upon life, keeping the pace for adopting a healthy lifestyle, and by decreasing the dosage of the oral antidiabetic medication by approximately $25 \%$ (fig. no. 1 ), up to $30 \%$ of the insulin units administered in some cases (fig. no 2), decrease by $35 \%$ of the medical leave days (fig. no. 3) and by $44 \%$ of the hospitalization days for the treatment of the complications of diabetes (fig. no. 4), the control of the comorbidity by decreasing the symptoms of depression (insomnia, eating behavior, depressive mood, anhedonia, ruminations), decrease of HBP by 10.4 units on average for the systolic blood pressure and 10.1 for the diastolic blood pressure (fig. no 5), decrease of the BMI from 34.3 to 31.5 on average (fig. no $6)$.

Conclusions. These results draw the attention once again upon the multiple directions of intervention and especially of prevention in case of the psychosomatic disease, especially of the diabetes mellitus, the CBT interventions, the schema therapy or the rational emotive behaviour therapy, foretelling the numerous ways of annulment, control or decrease of the psychical vulnerability to stress, that have major impact upon life. Thus, the costs with medical and social treatment (hospitalization for comorbidities or complication of diabetes mellitus, medical leave days, insulin or oral antidiabetic medication, medical retirement and so on) may decrease by 


\section{RESEARCH IN THE FIELD OF MEDICINE \\ THAT ELICIT LEGISLATIVE CHANGES IN THE HEALTH BUDGET}

aprox. $40 \%$. The budget for health gain is beneficial for both diabetic patients and equally for all of us, as taxpayers.

But psychology services are not reimbursed by health budget, making on the one hand that the addressing of these services to be restricted one, to be a luxury not access most of the patients and on the other hand the health budget has loss "hemorrhagic" funds of approx. 40\%, as shown above. It is necessary therefore necessarily, legislative changes allowing settlement of health insurance budget psychological intervention services, knowing that there is a practice of modern European of this type (in most European countries the cost of the first psychological intervention sessions 10-20 are borne by the health insurance budget).

\section{Bibliography}

1. Flaxman F.E., Blackledge J.T., Bond F. Acceptance and commitment therapy, "Routledge" Press, New York, 2011;

2. Rafaeli E., Bernstein D.P., Young J. - Schema Therapy, "Routledge" Press, New York, 2011;

3. Wehrenberg, M. - The 10 Best ever Depression Management Techniques, "W.W. Norton\& Company" Press, 2010;

4. Neimeyer R., Constructivist Psychotherapy - "Routledge" Press, New York, 2010;

5. Wehrenberg, M. - The 10 Best ever Anxiety Management Techniques, "W.W. Norton\& Company" Press, 2008;

6. Manjiri D. P., Roger T. A., Rajesh B. - Self-reported predictors of depressive symptomatology in an elderly population with type 2 diabetes mellitus: a prospective cohort study in: Health and Quality of Life Outcomes, p. 5-50, 2007;

7. Fradin, J. - Personnalité et psychophysiopathologie, nouvelle hypothèse en thérapie neurocognitive et comportamentale, "Publibook" Presse, Paris, 2006;

8. Davey, GCL, Wells, A - Worry and its Psychological Disorders: Theory, Assesment and Treatment, "J.Wiley \& Sons" Press, 2006;

9. Leahy, R. - Worry Cure, "Pitkus Books Ltd" Press, 2006;

10. Hilsenroth, M.J., Segal, D.L., Hersen, M. - Comprehensive Handbook of Psychological Assessment, in:Personality Assessment// Psychology. no. 466, 2004;

11. Fradin, J. - Gestion du stress et suivi nutritionnel, Paris, Presse Médecine et Nutrition, 2003; 12. Wells, A. - Emotional Disorders and Metacognition, Innovative Cognitive Therapy, "John Wiley \& Sons" Press, Ltd, UK, 2002;

13. Snyder, C.R. - Coping with stress: effective people and processes. - New York, "Oxford University" Press, 2001;

14. Iamandescu, I.B. - Psychoneuroallergology, "Romcartexim" Publishing House, Bucureşti, 1998 ;

15. Wells, A. -Cognitive Therapy of Anxiety Disorders: A Practice Manual and Conceptual Guide, "John Wiley \&sons" Press, 1997;

16. Iamandescu, I.B. - Psihologie medicala, second edition, "Infomedica" Publishing House, București, 1996;

17. Ikemi, Y.- Integration of Eastern and Western Psychosomatic Medicine, "Kyushu University" Press, Tokyo, 1995;

18. Vries H, Backbier E, Kok G, Dijkstra M - The impact of social influences in the context of attitude, self-efficacy, intention and previous behavior as predictors of smoking onset in: Journal Applied Social Psychology, no. 25, p: 237-257, 1995;

19. Brouschon, M., Danzer, R. - Introduction à la psychologie de la santé, Presse "Universitaire de France", Paris, 1994 ;

20. Young J. , Klosko J. , Reinventing your life, "Penguin Group" Press, New York, 1994;

21.Wells, A. Matthews, G. - Attention and Emotions: A Clinical Perpective, "Psychology" Press, UK, 1994; 


\section{D.S. Oieru , R.A. Popa}

22. Iamandescu, I.B. - Stressul psihic si bolile interne, "ALL " Publishing House, Bucureşti, 1993;

23. Folkman, S. and Lazarus, R.S. Coping and emotion in:A.Monat and R.S. Lazarus. Stress and Coping., New York, p. 207-227, 1991;

24. Kok GJ, de Vries H, Mudde AN, Strecher VJ - Planned health education and the role of selfefficacy: Dutch research in: Health Education Research, no 6, p 231-238, 1991;

25. Carver, C.S., Scheier, M.F., Weintraub, J.K. - Assessing coping strategies: a theoretically based approach in: Journal of Personality and Social Psychology. - vol. 56., p. 267-283, 1989;

26. Cohen, S., Edwards, J.R. - Personality characteristics as moderators of the relationship between stress and disorder, in R.W.Neufeld - Advances in the investigation of psychological stress, "J.Wiley \& Sons" Press, p.112-154, 1989;

27. Vries H, Dijkstra M, Kuhlman P - Self-efficacy: third factor besides attitude and subjective norm as a predictor of behavioral interventions in Health EducationResearch, no. 3, p. 273-282, 1988 ;

28. Leedom LJ, Meehan WP, Zeidler A - Avoidance responding in mice with diabetes mellitus in: Physiol Behav no. 40, p. 447-451, 1987;

29. D'Zurilla TJ, Nezu A - Social problem solving in adults in: Advances in cognitive behavioral research and therapy, 1st edition, p. 201-274, Kennedy PC. New York, Academic Press, 1987;

30. Lazarus, R.S., Folkman,, S.-, Transactional Theory and Research on emotions and coping, in: European Journal of Personality, no. 1, p. 141-169, 1987;

31. Lazarus, R.S. and Folkman, S. - The concept of coping. Stress and Coping, "Springer" Publishing Company, New York, 1986;

32. Stone, A., Neale, J.-New measure of daily coping: development and preliminary results in: Journal of Personality and Social Psychology, no. 46, p. 892-906, 1984;

33. Lazarus, R.S., Folkman, S.- Stress, Appraisal and Coping, "Springer" Publishing Company, NY, 1984;

34. Shaffer, M.- Life after Stress, "Plenum" Press, New York, 1982;

35. Wolfe, W.B. ,Adler A.- The Pattern of Life, Chicago, Alfred Adler Institute of Chicago, 2nd edition, 1982;

36. Kobassa, S. Stressful events, personality and health: An inquiry into hardiness in: Journal of Personality and Social Psychology, no. 37., p. 1-11, 1979;

37. Sarason, I.G., Johnson, J., Siegel, S.- Assessing the impact of life changes : development of the Life Experiences Survey, in: Journal of Consulting and Clinical Psychology, no.46, 932946, 1978;

38. D'Zurilla TJ, Goldfried MR - Problem solving and behavior modification in JAbnorm Psychol, no. 78, p. 107-126, 1971. 